\title{
The Costly Effects of US Water Fluoridation
}

\author{
Roger D. Masters* \\ Department of Government, Research Professor, Dartmouth College, Germany
}

Submission: July 14, 2017; Published: July 17, 2017

*Corresponding author: Roger D. Masters, Department of Government, Research Professor, Dartmouth College, Hanover, New Hampshire 03755, Germany, Email: roger.d.masters@dartmouth.edu

\section{Introduction}

Debates concerning the practice of "water fluoridation" in the U.S. have persisted over the years. Based on research concerning the effects of toxic chemicals, I've studied this issue for almost 20 years. Due to this research in neurotoxicology, I've often been asked about evidence either challenging or supporting practices of fluoridation in the U.S. As a result, I've prepared the following statement of my understanding of the scientific evidence on both sides of the debate.

First: There is an element in the "Table of Elements" called "fluorine" (with an "N"). It is not stable in isolation and forms compounds; in a compound it is called "fluoride" (with a "D"). Therefore, any discussion of its harmful effects needs to specific about the compound in which the fluoride is present at ingestion or other means of attaching to the human body.

Second: Toothpaste with sodium fluoride is apparently not a source of potential harm from the fluoride. The reason is that sodium fluoride "dissociates" immediately on addition to or in contact with water. $\mathrm{NaF}+\mathrm{H}_{2} \mathrm{O}===>\mathrm{Na}+\mathrm{F}+\mathrm{H}_{2} \mathrm{O}$. The free fluorine either bonds to tooth surfaces as fluoride or is likely to be excreted. (I know of no scientific test that finds otherwise).

Third: Water fluoridation is a totally different story. Like toothpaste, there is no problem with sodium fluoride, which is the compound only used for under $10 \%$ of the public whose water is fluoridated. For over $90 \%$ of those drinking fluoridated water, however, the compound used is either fluorosilicic acid $\left(\mathrm{H}_{2} \mathrm{SiF}_{6}\right)$ or sodium silicofluoride $\left(\mathrm{Na}_{2} \mathrm{SiF}_{6}\right)$ jointly called "silicofluorides" (SiF). Such water is delivered to over 140 million Americans. These compounds also "dissociate" into their basic elements when added to water though it's possible the atoms of silicon and fluorine could recombine to form either SiF4 (silicon tetrafluoride) or one of the silicofluorides. This issue is irrelevant to what follows, because the silicon atom is "covalent" (as one can see from the formulas $\mathrm{H}_{2} \mathrm{SiF}_{6}$ and $\mathrm{Na}_{2} \mathrm{SiF}_{6}$, $2+6=8$ ). Silicon's bonding potential was apparently the key to the problem of "silicone breast implants" insofar as the silicon atom could bond to other toxic chemicals. Of these potential toxins, lead is of particular importance as an element in many environments that, if bonded to silicon, would be carried into the body instead of being excreted in urine or feces.

Fourth: The harmful effects where silicofluorides are added to public water, the most frequent is high blood lead levels, but most important in terms of cost to taxpayers is apparently a highly significant increase in violent crime. Taking into consideration up to ten other socio-economic and environmental factors, other side effects increased by silicofluoride treated water include learning deficits and substance abuse (as measured by cocaine). In each case, each harmful outcome was analyzed with two or more different statistical tests (analysis of variance, multiple regression, step-wise regression, and factor analysis). Controlling for a variety of other factors, water treated with a silicofluoride compound was typically a major influence on the statistical frequency of harmful effects observed in U.S. populations.

Fifth: The history of water fluoridation is also essential, because it explains why the practice of fluoridation with a silicofluoride compound has never been subjected to laboratory tests of its safety. This practice was initiated for reasons that had nothing whatever to do with dental caries or other aspects of dental health. My co-author and colleague, the late Myron J. Coplan, was a chemist who had played a direct role in the initiation of adding a fluoride compound to public water supplies in Feb. 1942. The compound was fluorosilicic acid (H2SiF6), a highly acidic chemical widely used to etch metal, which was selected to separate uranium from phosphate rocks in order to develop the A-bomb in America. Starting the Manhattan Project immediately after Dec. 7, 1941 was necessary because Hitler had joined Japan in declaring war on the U.S. After the occupation of Czechoslovakia had given Germany access to high quality uranium mines, moreover, Hitler had already started an Atomic bomb project. (Einstein's famous letter to FDR in 1938, advising of this possible weapon, reflected information that was known by the other nuclear physicists with whom he had worked in Germany.) 
The only uranium within the continental U.S. was in phosphate rock. Hence it was necessary to grind up these rocks and use the highly acidic H2SiF6 to break down the rock's chemical bonds. The resulting mixture of fluorosilicic acid and basic elements from the rock was then put in a centrifuge. Uranium 238, as the heaviest element, was easy to separate in a centrifuge. Then a filter was needed to separate the remaining solids from the fluorosilicic acid. All this had to be highly secret. Mr. Coplan was a specialist the chemistry of filters and played a role in developing the filters used in this process by the Manhattan Project. As a result, he knew first hand that after the separation of fluorosilicic acid from solids, it was decided to dispose of the left-over toxic H2SiF6 in a public water system (on the assumption that, like sodium fluoride, it would "dissociate" into its three component elements).

Speaking only of "water fluoridation" as a health measure, the first test was adding sodium fluoride to an American water system. For this purpose, the first test was in a comparison of Newburgh \& Kingston, NY were selected, with sodium fluoride added to one city and the other used as a control. Since sodium fluoride was considered safe due to its use in toothpaste, the announcement of its addition to public water as a health measure was widely distributed and backed by the American Dental Association and the American Medical Association. A major press campaign followed, largely on its own momentum, favoring water fluoridation and since sodium fluoride was added, little or no mention was made about the compound used. Once the concept of "water fluoridation" was accepted and the practice always described without mention of the chemical compounds used, a "bait and switch" strategy allowed the Manhattan Project to substitute fluorosilicic acid without gaining the attention of the public.

Sixth: Ironically, the gambit of speaking only of "fluoridation" worked so well that it still dominates the discussion of this entire issue, as is indicated by continued controversy over "water fluoridation" in which neither supporters nor critics ever mention there is a choice between sodium fluoride (NaF) and one of the two silicofluorides (either $\mathrm{H} 2 \mathrm{SiF} 6$ or $\mathrm{Na}_{2} \mathrm{SiF}_{6}$ ).For critics, all fluoride compounds are equally dangerous just as, for supporters, all fluoride compounds are safe and beneficial.

Seventh: The publications of Coplan\& Masters provide statistically significant evidence that there are many harmful side-effects of water fluoridation with a silicofluoride:

a. Higher children's blood lead (with greater effects on Blacks than on Whites, and greater effects for

b. Iower educational performance (e.g., as measured by scores on standardized tests in different subjects and grades, as well as by school drop-out rates)

c. Higher rates of substance abuse (measured by cocaine)

d. higher rates of violent crime (confirmed by multivariate statistics, controlling for up to ten other related factors like income, population density, and ethnicity)

The dollar cost of the first three harmful effects is more difficult to estimate than the specific dollar costs to taxpayers of higher violent crime rates. From some published figures, a year in prison costs between $\$ 30,000$ and $\$ 50,000$ per inmate. As a rough estimate, therefore, the national cost of violent crime is in the hundreds of million dollars. If so, the total cost of using silicofluorides in the U.S is probably at least $\$ 1,000,000,000$ (that's $\$ 1$ billion) a year.

Eighth: Given the foregoing summary of almost two decades of peer reviewed scientific studies, the policy proposal of a moratorium on adding either silicofluoride to water seems reasonable. The concept of a "moratorium" is appropriate since use of these compounds should resume if peer reviewed laboratory tests and field studies not only provided evidence of silico-fluoride's safety, but showed the errors in existing peer reviewed scientific publications. Pending completion of such research studies, a moratorium would also allow time to measure whether permanently ending silicofluorides would benefiter harm dental health and increase or lower rates of the costly outcomes just noted.

Ninth: Consider the irony of this issue. Each year, government deficits seem to rise without end at the local, state, and national levels. This memorandum proposes a simple step, with virtually no cost (all that's required is to turn OFF the valves for adding silicofluorides to public water systems) that has the potential of cutting as much as $\$ 1$ billion dollars from current budget deficits.

Tenth: One root problem with water fluoridation is that American mass media has failed to cover the above scientific findings (perhaps because this challenge to the use of silicofluorides is bound to be controversial). The consequence is a lack of information among the general public(as well as Washington's decision-makers) combined with the customary belief that water fluoridation is essential for the dental health of the poor (or ignorant) who don't brush their teeth.

\section{Conclusion}

I will be happy to debate, on national television, any representative of the American Dental Association who is willing to defend the current practice of adding silicofluorides to the public water systems of an estimated 140 million Americans. If a live debate, I would welcome an opportunity to present these findings to American voters on TV, or even more relevant in a legislative hearing on legislation for a 10 year moratorium (permitting a population test of the costs and benefits of water fluoridation with silicofluorides. Such a test is far better than the laboratory studies of small samples, especially because findings to date have demonstrated consistently that communities using silicofluoride in water treatment have higher children's blood levels, and increased rates of violent crime, substance abuse, and learning deficits. If this is not possible, I'll be happy to testify under 
oath at either a court case on a suit to halt use of silicofluorides in a community, a state, or the entire U.S either permanently or for a test period of at least 10 years. If legislation to this effect, I'd of course be willing to testify under oath at Congressional committee hearing or if not possible, a comparable committee of one or more state legislatures. It's worth added that proponents of water fluoridation have consistently refused to debate now that there are almost two decades of scientific data contradicting their claims.

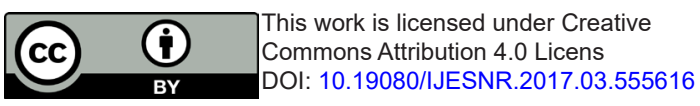

\section{Your next submission with Juniper Publishers will reach you the below assets}

- Quality Editorial service

- Swift Peer Review

- Reprints availability

- E-prints Service

- Manuscript Podcast for convenient understanding

- Global attainment for your research

- Manuscript accessibility in different formats ( Pdf, E-pub, Full Text, Audio)

- Unceasing customer service

Track the below URL for one-step submission https://juniperpublishers.com/online-submission.php 